\title{
Hazards of lung biopsy in asbestos workers
}

\author{
Y LERMAN, J RIBAK, AND I J SELIKOFF
}

From the Environmental Sciences Laboratory, Mount Sinai School of Medicine of the City University of New York, New York, New York 10029, USA

ABSTRACT An investigation into the problem of the frequency and hazards of lung biopsy in asbestos workers was performed in two ways. The first study was into the frequency of lung biopsy among 2907 long term asbestos insulation workers in 1981-3 and the second was into the frequency of fatal complications of lung biopsy in 168 deaths from asbestosis among 2271 consecutive deaths of asbestos insulation workers 1967-76. Only $25(0.9 \%)$ of the 2907 asbestos insulation workers reported having had either an open lung biopsy, a needle biopsy, or a transbronchial biopsy. Seven $(24 \%)$ of these men suffered difficulties as a result of the biopsy. Lung biopsies had been performed on 14 of the 168 workers who died of asbestosis. Three $(21 \%)$ of these 14 patients had died within 30 days of biopsy as a direct result of the procedure. In most cases there is no need for lung biopsy to establish a diagnosis of asbestosis; generally, it may be defined by history of exposure, clinical and radiological findings, and other well established non-invasive diagnostic procedures. Certainly, legal and compensation recommendation for biopsy should be considered with the possibility of death in mind. If biopsy is performed precautions should be taken, including adequate observation in hospital.

Diffuse interstitial fibrosis of the lung, fibrotic thickening of the pleura with or without calcification, malignant mesothelioma of the pleura and peritoneum, carcinoma of the lung, and other cancers are associated with exposure to asbestos. ${ }^{12}$ The different clinical methods used diagnosing these asbestos related conditions include a thorough occupational history, taking into account the long period of clinical latency between onset of exposure and clinical manifestation of disease ${ }^{3}$; clinical signs and symptoms, such as shortness of breath first noted with exercise, crepitations (crackles, rales) sometimes occurring late in inspiration, usually over the lower and middle lung zones; and clubbing of the fingers and toes. Radiographic changes, such as small irregular opacities and pleural fibrosis and calcification, ${ }^{4}$ ventilatory dysfunction (primarily of a restrictive pattern), and gas exchange impairment in pulmonary function testing ${ }^{5}$ add much in establishing a diagnosis of asbestosis.

With this array of well established diagnostic approaches, biopsy of peripheral lung tissue is unlikely to be necessary except for a relatively limited number of cases, in which the clinical findings and laboratory tests do not yield a clear diagnosis and where tissue analysis might disclose treatable disease.

Accepted 23 July 1985
Although lung biopsy for diffuse pulmonary diseases is in general a relatively safe and useful procedure, in some cases the procedure may be complicated and may lead to serious and even fatal complications, ${ }^{6-9}$ reminiscent of difficulties seen in patients with tuberculosis with impaired pulmonary reserve who suffered lung trauma during pneumothorax treatment. ${ }^{10}$

We have investigated this problem in patients with asbestosis and report here on the frequency of lung biopsy in two cohorts of living and dead asbestos workers and describe three cases in which death occurred after lung biopsy in patients with asbestosis.

\section{Materials and methods}

A cohort of asbestos insulation workers in the United States and Canada was established on 1 January $1967 .{ }^{11}$ It included all 17800 men on the rolls of the insulation workers union, the International Association of Heat and Frost Insulators and Asbestos Workers (IAHFIAW), AFL-CIO, CIC, in the United States and Canada on that day. All deaths among these men have since been noted and investigated. ${ }^{11}$ There were 168 fatal cases of asbestosis among the 2271 consecutive deaths which occurred during 1967-76. ${ }^{11}$ Among these were 14 in which biopsy had been performed. Three had died. 
Frequency of lung biopsy and complications among 2907 asbestos insulation workers

\begin{tabular}{|c|c|c|c|c|c|}
\hline Procedure & Total No & Reason for biopsy & No & Postoperative problems & No \\
\hline Open lung biopsy & 12 & $\begin{array}{l}\text { Confirm diagnosis of } \\
\text { asbestosis } \\
\text { Rule out malignancy }\end{array}$ & $\begin{array}{l}5 \\
7\end{array}$ & $\begin{array}{l}\text { Pneumonia with abscess } \\
\text { formation } \\
\text { Persistent pain at } \\
\text { operation site }\end{array}$ & $\begin{array}{l}1 \\
4\end{array}$ \\
\hline Needle lung biopsy & 4 & $\begin{array}{l}\text { Confirm diagnosis of } \\
\text { asbestosis } \\
\text { Pleural effusion recurrent } \\
\text { Rule out malignancy }\end{array}$ & $\begin{array}{l}1 \\
1 \\
2\end{array}$ & $\begin{array}{l}\text { Pneumothorax } \\
\text { Protracted healing of } \\
\text { operation wound }\end{array}$ & $\begin{array}{l}1 \\
1\end{array}$ \\
\hline Transbronchial biopsy & 9 & $\begin{array}{l}\text { Confirm diagnosis of } \\
\text { asbestosis } \\
\text { Rule out malignancy }\end{array}$ & $\begin{array}{l}5 \\
4\end{array}$ & & \\
\hline Total & 25 & $\begin{array}{l}\text { Confirm diagnosis of } \\
\text { asbestosis } \\
\text { Rule out malignancy } \\
\text { Recurrent pleural effusion }\end{array}$ & $\begin{array}{r}11 \\
13 \\
1\end{array}$ & & \\
\hline
\end{tabular}

*Interestingly two of seven had malignancy.

All patients had unequivocal $x$ ray changes consistent with asbestosis.

In a second study 5377 members of the original cohort who were still alive in 1981 and had reached 30 years from onset of exposure to asbestos were invited to attend for a comprehensive medical examination in a survey of their medical status; 2907 appeared and were examined in 1981-3.* The examination included occupational history and respiratory questionnaires, physical examination, chest $x$ ray films, pulmonary function studies, and laboratory tests. We have analysed the 2907 cases with regard to lung biopsies that had been performed. Information was obtained from each examinee with a history of lung biopsy about the nature of the procedure, the course, and any complications noted after biopsy. We thus have two sets of data; firstly, the frequency of lung biopsy among asbestos insulation workers from our samples of 2907 examined living workers and, secondly, the frequency of lung biopsy and the occurrence of fatal complications in 2271 deaths among asbestos insulation worker 1967-76.

The frequency of open lung biopsy, needle biopsy, and transbronchial biopsy among the 2907 insulation workers is shown in the table which also includes reason(s) for performing the biopsy and any postbiopsy difficulties as reported by the patients. Twelve men $(0.44 \%)$ had undergone open lung biopsy. Reasons included confirmation of suspected asbestosis in five and search for malignancy in seven. One had pneumonia with abscess formation after open lung biopsy and four indicated that they had persistent pain at the operation site for many months after surgery. Of the four patients who had had needle

\footnotetext{
*Examinations were undertaken in Chicago, Columbus, Baltimore, Boston, Atlanta, Tampa, Seattle, Anchorage, San Francisco, Los Angeles, Denver, Omaha, St Louis, Albuquerque, Dallas, Houston, New Orleans, New York-New Jersey, Syracuse, from November 1981 to October 1983.
}

biopsy, one developed pneumothorax. Nine had undergone transbronchial biopsy without complication.

Fatal outcome of biopsy could not be studied in $\mathrm{a}_{\vec{Z}}$ cross sectional clinical survey. For this, we investigated experiences in our mortality study. Four- $\frac{\widehat{S}}{\gamma}$ teen lung biopsies $(8 \cdot 3 \%)$ had been performed among $\vec{\oplus}$ 168 fatal cases of asbestosis. Four were open lung ${ }_{\circ}^{\circ}$ biopsies, three transbronchial, and seven needle. Three $(21 \%)$ of these 14 patients died less than 30 days after the biopsy. Two additional patients with asbestosis died after diagnostic surgical procedures. One $\bar{O}$ underwent thoracotomy for suspected cancer (none was present). Extensive pleural fibrosis was found and $\stackrel{\mathbb{Q}}{\mathbb{Q}}$ decortication was decided on. Massive subcutaneous $\vec{\overrightarrow{ }}$ emphysema developed and the patient died on the 3 seventh postoperative day. Another patient developed bronchopleural fistula and empyema after thora-o cotomy and resection (again, no cancer was present) and died.

\section{Case reports of deaths after lung biopsy}

\section{CASE 1}

A 48 year old white man who had been an insulation? worker for 21 years was admitted to hospital in June $>$ 1972 with a history of one year of shortness of breath, productive cough, and episodes of haemoptysis. His N medical history was unremarkable. A grandmotherhad had tuberculosis. The patient was a cigar smoker; 0 there was no history of cigarette smoking. Chest $x$ ray N films were interpreted as showing a reticular pattern of interstitial disease confined to the left lower lung fieldo and pleural thickening over the right lateral hemithorax. A poorly defined nodular opacity in the left $\stackrel{?}{+}$ upper lobe and prominence of the left hilum were noted. Left thoracotomy was performed on 16 Juneo 1972 and the nodule was sharply excised. A prominent 
grey white focally nodular thickening of the parietal pleura along the hilar region of the mediastinum was seen and a biopsy of the margin of this area was taken. Pathological study of the surgical specimens showed diffuse interstitial fibrosis and asbestos bodies, a calcified granuloma, and pronounced pleural fibrosis. The patient left the operating room in good condition. A raised temperature was soon noted with spiking temperature the next day when he developed septic shock. Exploration of the operative wound showed an extensive area of necrosis. Sharp dissection and excision of the skin and underlying muscles were performed. Coagulase positive Staphylococcus aureus was cultured from the chest wall tissue. He left the operating room in poor condition and suffered cardiac arrest. After successful resuscitation, he developed acute renal failure and was dialysed through an A-V shunt. There was considerable difficulty maintaining his blood pressure and despite dialysis, the serum potassium remained raised $(7.1 \mathrm{meq} / \mathrm{l})$. On 23 June 1972 he died after a second cardiac arrest.

The gross pathological diagnosis at necropsy was: history of necrotising myositis of left thoracic wall, surgical absence of left thoracic wall, pulmonary oedema, asbestosis, early haemorrhagic necrosis of colon, pleural fibrosis and probably fatty metamorphosis of liver. The final cause of death was asbestosis.

\section{CASE 2}

A 62 year old white man with a history of 47 years of exposure to asbestos was admitted to a hospital on 10 June 1968 for evaluation of shortness of breath and chest pain which had gradually developed over the previous four years. Chest $x$ ray films showed a diffuse fine granular appearance throughout both lung fields, particularly in the lower two thirds. The same changes were noted on chest $x$ ray films of 1966. Pulmonary function tests were reported consistent with a moderate degree of pulmonary insufficiency; actual figures are not available. The exact aetiology of the diffuse granularity could not be stated and pneumoconiosis or collagen disease were considered as possibilities. A needle lung biopsy was performed on 17 June 1968 and showed diffuse interstitial fibrosis and pneumonitis. The patient became dyspnoeic after the biopsy and developed pneumothorax and subcutaneous emphysema and died on 21 June 1968 after cardiac arrest. The cause of death was attributed at necropsy to extensive diffuse pulmonary fibrosis associated with previous exposure to asbestos and cardiac decompensation.

\section{CASE 3}

A 60 year old white man was admitted to hospital on 25 April 1972 with a history of five years of increasing shortness of breath and recurrent pleural effusion re- quiring frequent thoracenteses. His medical history showed a heart murmur of mitral heart disease that had been detected in 1967 and acute renal failure due to a drug reaction in 1944. He had smoked two packets of cigarettes a day for $\mathbf{3 0}$ years. Physical examination showed an elderly cachectic man in severe respiratory distress; his blood pressure was $118 / 78$ $\mathrm{mm} \mathrm{Hg}$ and pulse rate $98 /$ minute, irregular. A grade $2 / 6$ mid-systolic rumble was heard at the apex and a grade $3 / 6$ early diastolic blow murmur at the left lower sternal border. Breath sounds were diminished bilaterally. Rhonchi and rales were heard mostly over the right side. An electrocardiogram showed atrial fibrillation with a rate of 78 /minute ventricular response and incomplete right bundle branch block. The chest $x$ ray film showed a right pleural effusion and pleural fibrotic changes on the left. The lung fields had limited profusion of small opacities. Pulmonary function studies showed a pronounced reduction in lung volumes and diffusing capacity. The patient's dyspnoea did not improve despite aggressive treatment with digoxin, diuretics, and bronchodilators. A right pleural biopsy was performed on 28 April 1972 as a malignant pleural process was suspected. The surgical specimen showed chronic inflammatory change. The patient was extremely anxious after the biopsy and was hyperventilating. He received oxygen, and intermittent positive pressure breathing was given frequently. He died on 29 April 1972 after he was found to be apnoeic and in cardiac arrest.

The immediate cause of death was respiratory failure. At necropsy, the major gross anatomical findings were bilateral pleural effusion with pleural thickening, mitral stenosis, and calcification secondary to rheumatic valvulitis; bilateral pulmonary oedema and congestion; there was extensive diffuse interstitial fibrosis and asbestos bodies.

\section{Discussion}

FREQUENCY OF LUNG BIOPSY IN ASBESTOSIS

Our data indicate that lung biopsy among asbestos insulation workers is rare. Thus only $25(0.09 \%)$ of 2907 asbestos insulation workers with more than 30 years since onset of exposure to asbestos reported either an open lung biopsy, a needle biopsy, or a transbronchial biopsy.

The frequency of lung biopsy in this group of insulation workers with more than $\mathbf{3 0}$ years from onset of exposure is probably not representative of the frequency of this diagnostic procedure among asbestos exposed workers in general; possibly in groups with shorter times from onset of asbestos exposure the frequency of lung biopsy would be lower.

Two $(8 \%)$ of the 25 patients had major postbiopsy 
complications (abscess formation, pneumothorax).

The experience in our mortality series is also consistent with infrequency of lung biopsy among cases of asbestosis. Thus only $14(8.3 \%)$ of the 168 cases of deaths of asbestosis encountered among 2271 consecutive deaths during 1967-76 had undergone lung biopsy.

\section{HAZARDS OF LUNG BIOPSY IN ASBESTOSIS}

The fact that the frequency of lung biopsy among live and dead asbestos insulation workers is relatively low is the background against which the three fatal complications of lung biopsy are to be viewed. The immediate causes of death in these cases were septic shock and arrhythmia in a case of open lung biopsy, pneumothorax and subcutaneous emphysema after a needle biopsy, and respiratory failure in a case of pleural biopsy in which bilateral pleural effusion and rheumatic mitral valve disease were present.

Several techniques for lung biopsy have been used in the past decades. Several studies ${ }^{6-912-17}$ have summarised experiences with different techniques; the results varied according to the method of biopsy, experience of the surgeon, and the relative incidence of diffuse interstitial fibrosis among patients.

Open lung biopsy for diffuse pulmonary disease was accepted as a safe and valuable diagnostic procedure during the 1960 s, after the first large series reported by Klassen ${ }^{18}$ in 1949. Aaron et al reported rare instances of atelectasis after open lung biopsy, requiring transtracheal suction and other local measures, and accumulation of pleural fluid or air, requiring thoracentesis or reinsertion of a chest tube. ${ }^{6}$ The two deaths that occurred within 30 days of surgery in Aaron's series were directly related to the underlying disease, although the surgical procedure might have contributed. Of interest in that series was the absence of cases of pneumoconioses; this was explained by the authors as related to the fact that the patients came from a military population.

Gaensler and Carrington reviewed their experience with 502 patients who had open lung biopsy for chronic interstitial lung disease. ${ }^{13}$ Only one death $(0.3 \%)$ occurred within 30 days, of a severely ill, 60 year old man who had bronchiolar alveolar cell carcinoma and multiple pulmonary emboli, together with nine $(2.5 \%)$ major complications and nine minor complications. Additional experiences with open lung biopsy were reported by Hill et al with no postoperative death among 42 patients who underwent open lung biopsy during an early phase of acute respiratory insufficiency. ${ }^{12}$ The different incidence of diffuse interstitial fibrosis among the patients studied might explain the reported differences in postbiopsy mortality in different reports. Thus in another study three $(7 \cdot 3 \%)$ patients died within 40 days after biopsy, explained by the higher incidence of diffuse interstitial fibrosis or pneumonitis among patients; two of the? deaths occurred in patients with diffuse interstitial $\overrightarrow{\vec{F}}$ fibrosis. ${ }^{7}$ The third death occurred in a patient who $\stackrel{?}{+}$ had both interstitial fibrosis and pneumonitis. The one death that was secondary to a tension pneu- $\frac{\bar{\sigma}}{\bar{c}}$. mothorax apparently was caused by the procedure. In $\frac{\bar{\sigma}}{\widetilde{\sigma}}$ the other two cases death appeared to result from theo underlying disease but the operation probably con-क tributed to the outcome.

The same variability of the postbiopsy mortality: rate is found in studies of needle lung biopsy and $\vec{\omega}$ transbronchial biopsy. Needle biopsy as another means of establishing a histological diagnosis in pa-更 tients with diffuse interstitial disease was introduced? in the early 1960s. Walton and Skeoch reported onct their experience with over 200 needle lung biopsies $\omega$ without fatality but reported that the procedure $\vec{F}$ should be used only in a hospital where full thoracic surgical facilities were immediately available. ${ }^{14}$ This $^{\supset}$ excellent experience was not shared by Mann and $\vec{z}$ Sinka who reported on 50 patients with suspectedo

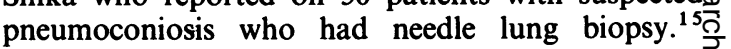
Twelve had traumatic pneumothorax, of whom eight required an intercostal catheter and mechanical suc $-\infty$ tion.

The use of bronchoscopy for visualisation of the respiratory tract with transbronchial biopsy became popular in the beginning of the 1970s. Credle et al reported that the incidence of all complications associated with flexible fibreoptic bronchoscopic exam- $\stackrel{\square}{\square}$ ination was less than $0.1 \% .{ }^{17}$ Suralt and his $\underset{\overrightarrow{0}}{\overrightarrow{0}}$ colleagues reported an overall rate of complication of $\frac{0}{3}$ $0.3 \%$. ${ }^{9}$ Twelve deaths and 45 life threatening complications were included in this study. Apparently car-0 diac arrhythmias associated with premedication or the administration of anaesthetics were the major $\frac{\mathbb{D}}{3}$ causes of death associated with bronchoscopy. It was evident from this study that precautions must be 3 . taken when bronchoscopy is considered in elderly patients.

The three postbiopsy fatal complications reported $\circ$ by us, and other reported cases $^{8}$ raise the question of re-evaluation of indications and contraindications of $D$ this procedure, particularly in asbestosis. Our experience would suggest that in most cases there is no need $N$ for lung biopsy to establish a diagnosis of asbestosis; an adequate and accurate history of exposure, taking N into account the fact that asbestos and most other ${ }_{\sigma}^{\omega}$ pneumoconioses often do not become clinically manifest until decades after first exposure, ${ }^{3}$ can facilitate diagnosis and expedite appropriate treatment. Even $\mathrm{a}_{\mathscr{\Phi}}$ brief exposure, sometimes during temporary employment, such as a summer job, lasting for only a few weeks, may be extremely important ${ }^{19}$; often the pa- $\frac{\vec{\Phi}}{\Phi}$ tient does not recall short term exposure until the $\frac{\rho}{\mathrm{Q}}$ 
physician probes for such detail. With neoplasms, careful physical examination may sometimes disclose extrapulmonary involvement of skin or lymph nodes which may be more safely biopsied than the lung. ${ }^{20}$ Careful interpretation of the routine chest $x$ ray film, including assessment of pleural thickening, calcification, and plaques on the diaphragmatic surfaces, which are virtually pathognomonic for asbestosis, as well as comparison with previous $x$ ray films, can frequently obviate unnecessary lung biopsy to confirm the diagnosis of asbestosis. ${ }^{20}$

In those cases where the indication for doing the biopsy is to rule out malignancy, new less invasive techniques, such as computed tomography scan of the chest together with transbronchial biopsy are often available. The risk of each procedure has to be balanced against the potential benefits in the individual case and the physician must judge whether possible therapeutic benefits outweigh the risks. If they do biopsy would be warranted. (In this regard, it is of interest that $\mathbf{4 8 6}$ fatal cases of lung cancer, of whom $179(36 \%)$ were biopsied and 63 cases of pleural mesothelioma, of whom $38(60 \%)$ were biopsied, were also found among the 2271 consecutive deaths. None died as a result of these biopsies.) Moreover, there is little value in performing lung biopsy if the clinical condition of the patient precludes acting on the information obtained. Case 3 presented in this study seems to fall into this category.

The causes for the increased risk of postbiopsy death among asbestos workers may vary. Humoral and cellular immunological alterations have been reported in animal studies and in individuals with asbestosis. ${ }^{21}$ Such a mechanism might explain the development of septic shock and death in case 1 . Reduction of the functional reserve of the lung ${ }^{5}$ probably occurred in cases 2 and 3. Here, the lung cannot remain at rest to facilitate healing ${ }^{10}$ and the "stiff" fibrotic lung might not readily retract to help the process.

\section{Conclusion}

The benefit of having lung tissue to diagnose asbestos related diseases should be weighed in each case against the risk of postbiopsy death. Lung biopsy is indicated in those cases in which the clinical findings and laboratory tests are not specific enough to rule out treatable conditions. Lung biopsy is not advised for "legal" reasons to confirm the diagnosis of asbestosis which can usually be diagnosed without invasive tests. When biopsy is performed appropriate precautions have to be taken and adequate observation in hospital is recommended.

Requests for reprints to: I J Selikoff, MD, Environmental Sciences Laboratory, Department of Community Medicine, Mount Sinai School of Medicine, 1 Gustave L Levy Place, New York, NY 10029.

\section{References}

${ }^{1}$ Selikoff IJ, Lee DHK. Asbestos and disease. New York: Academic Press, 1978:135-41.

2 Becklake, MR. Asbestos-related diseases of the lung and other organs; their epidemiology and implications for clinical practice. Am Rev Respir Disease 1976;114:187-220.

${ }^{3}$ Selikoff IJ, Hammond EC, Seidman H. Latency of asbestos disease among insulation workers in the United States and Canada. Cancer 1980;46:2736-40.

${ }^{4}$ International Labour Office. The ILO international classification of radiographs of pneumoconioses, 1980. Geneva: ILO, 1980. (Occupational safety and health series, No 22 (rev).)

${ }^{5}$ Becklake MR. Lung function. In: Bogovski P, Jilsen JC, Timbrill V, Wagner JC, eds. Biological effects of asbestos. Lyon: IARC, 1973:39. (IARC scientific publication No 8.)

${ }^{6}$ Aaron BL, Bellinger SB, Shepared BM, et al. Open lung biopsy: a strong stand. Chest 1971;59:18-22.

${ }^{7}$ Baker RR, Lee JM, Carter D. An evaluation of open lung biopsy. Hopkins Med J 1973;132:103-16.

${ }^{8}$ Scadding JG. Lung biopsy in the diagnosis of diffuse lung disease. Br Med J 1970;ii:557-64.

${ }^{9}$ Suralt PM, Smiddy JF, Gruber B. Deaths and complications associated with fiberoptic bronchoscopy. Chest 1976;69:747-51.

${ }^{10}$ Selikoff IJ, Tchertkoff IG, Robitzek EH. Initial pneumothorax: a new safe induction technique. Quarterly Bulletin of Sea View Hospital 1948;10:93-100.

${ }^{11}$ Selikoff IJ, Hammond EC, Seidman H. Mortality experience of insulation workers in the United States and Canada 1943-1976. Ann NY Acad Sci 1979;330:91-116.

12 Hill JD, Ratliff JL, Parrott JCW, et al. Pulmonary pathology in acute respiratory insufficiency. Lung biopsy as a diagnostic tool. $J$ Thorac Cardiovasc Surg 1976;71:64-71.

${ }^{13}$ Gaensler EA, Carrington CB. Open biopsy for chronic diffuse infiltrative lung disease. Clinical, roentgenographic and physiological correlation in 502 patients. Ann Thorac Surg 1980;30:411-26.

${ }^{14}$ Walton M, Skeoch T. Diagnosis of asbestosis by needle lung biopsy. Thorax 1968;23:556-62.

15 Mann B, Sinka CN. Jack needle lung biopsy in pneumoconiosis. Diseases of the Chest 1966;50:504-8.

${ }^{16} \mathrm{~K}$ han MA, Whitcomb ME. Deaths associated with flexible bronchoscopy. Chest 1976;70:200-1.

${ }^{17}$ Credle WR, Smiddy JF, Eliott RC. Complications of fiberoptic bronchoscopy. Am Rev Respir Dis 1974;109:67-72.

${ }^{18}$ Klassen KP, Anlyan AJ, Curtis GM. Biopsy of diffuse pulmonary lesions. Arch Surg 1949;59:694-704.

${ }^{19}$ Seidman H, Selikoff IJ, Hammond EC. Short-term asbestos work exposure and long-term observation. Ann NY Acad Sci 1979;330:81-90.

${ }^{20}$ Neff TA. Lung biopsy. How vs Whom. Chest 1976;70:201-2.

${ }^{21}$ Doll NJ, Stankus RP, Barkman WH. Immunopathogenesis of asbestosis, silicosis and coal workers pneumoconiosis clinics. Chest Medicine 1983;4:3-14. 